\title{
CROSS-BINARY NETWORK AND OTHER MAJOR GROUNDS FOR TEACHING VOCABULARY TO ADVANCED LEARNERS OF ENGLISH
}

\author{
Abdullah Al Mahmud ${ }^{1 *}$, Amatussalam Kaosar ${ }^{2}$ \\ ${ }^{1}$ Senior Lecturer, Linton University College, Malaysia \\ ${ }^{2}$ Eastern University Bangladesh \\ *E-Mail: abdullahalmahmud1980@gmail.com \\ Phone: +60146618404
}

\begin{abstract}
As the main ingredient of language, vocabulary has ever been a component of the English language teaching-learning courses in both organized and incidental ways. Also, various strategies or techniques of vocabulary-teaching have been proposed by multiple scholars, but the grounds underlying these strategies have remained sporadic and without particular emphasis on the need of the advanced learners. With this view in mind and by taking the advanced or university-level learners as a discrete group, this knowledge-based documentary article sorts out five noteworthy broad 'grounds' of consideration for teachers and learners of vocabulary. Along with introducing a 'crossbinary network' of comparative vocabularies of four skills, the said grounds bring together the common principles behind most of the acceptable vocabulary-teaching strategies. While Bangladesh has been used for reference and contextualization, the ideas provided may be practicable in teaching advanced learners anywhere else with a similar situation.
\end{abstract}

Key words: ELT, Vocabulary, Advanced Learners, Schema, Memory

\section{INTRODUCTION}

Everything we speak and listen or read and write in a language is nothing but a collection of words. But the collection is not an arbitrary or accidental one; rather the words are chosen in a certain order necessary to convey an intended meaning. In this process, vocabulary functions like ingredients while the four skills are recipes for cooking (processing) them for a visible (reading-writing) or audible (listening-speaking) communication outcome. Moreover, the meanings and words do not have a one-to-one relationship. Vocabulary is rather a multifaceted phenomenon relative to linguistic and situational contexts, and dependent on the user's intention as well as the receiver's perception. The more a learner advances, the more this multifariousness is felt and faced.

In spite of this, English vocabulary teaching and learning in Bangladesh is accomplished by conventional methods with a simplistic approach, which does not seem to address the afore-mentioned complex side of vocabulary. As a result, even after completing English courses at primary, secondary and higher secondary levels, lack of appropriate and adequate vocabulary remains as one major hurdle for university students' performance in English and thereby for their general study progress. The crisis for learners of this level reaches the peak 
due to the discipline-specific subjects, where most books are still in English and a more sophisticated vocabulary range is involved.

\subsection{EFL ${ }^{1}$ vocabulary teaching in Bangladesh and the advanced learners}

Since language involves a continuous combination of words for intended meanings, language teaching models generally include the component of vocabulary and grammar along with the four universal language skills, though with varied emphasis and manifestations. The conventional teaching of vocabulary in Bangladesh secondary and higher secondary education is mostly incidental, limited to explaining new items as they appear in reading or occasional listening tracks. This practice assumes that vocabulary enrichment occurs just through a repeated drill of necessary new words. However, this method has been proved inadequate (Schmitt, 2000). The poor vocabulary level of high school and college graduates in Bangladesh presents enough evidence of this (Arju, 2011). In spite of having English subjects in each class all through the twelve years of primary and secondary education, most students are deficient in using the right words at the right places and lack the stock of everyday words, let alone the vocabulary they are going to confront in the upcoming higher study subjects. The only exceptions are those who used to read out-of-syllabus English books for individual pleasure (personal informal interview notes, 2009-2018). These students' perceived good condition in vocabulary is due to nothing but the continuous exposure of English words and phrases that they acquire as a natural outcome of their personal reading habit. Thus, sources other than a school or college syllabi and formal teaching practices are the main contributors to building or increasing these students' word stock.

Next, there had been a shift from the age long Grammar Translation Method (GTM) to Communicative Language Teaching (CLT), and it became (and still is) the official government education policy from the year 2001 (Yasmin, 2006). The popular ground for this official change is based on the notion that traditional method has failed and is deficient, whereas CLT will succeed and is efficient. During GTM days, vocabulary teaching absolutely depended on the words found in the literary texts in the syllabus (Rahman, 1988), most of which would go above the students' heads. After CLT has come, things have changed a little, as the language books at the high school classes now mostly consist of conversational texts or short informational essays on everyday topics (Yasmin, 2006). As a positive result of this, tertiary students in Bangladesh now can generally use or at least comprehend the basic communication words. The same fact implies its limit too.

Therefore, the real difficulty starts when in a year or so after entering universities students have to comprehend a lot of academic books and articles. They feel handicapped in the face of a high range of academic and discipline-specific vocabulary. A small fraction of university students are diligent enough to overcome this problem by giving personal extra efforts, but the remaining large number of them lose hope to grasp the subjects due to language barrier and therefore depend on the senior students' notes or tutorial classes in the mother tongue Bengali (personal informal interview notes, 2010-2018). This also may explain why in Bangladesh and the similar countries the dependency on seniors' notes is the main hope of the majority of university students. Obviously, what these students need to get over this hurdle is to broaden their vocabulary with an emphasis on comprehending the academic books of their undergraduate courses and to express their ideas in different disciplines in a minimum acceptable way.

\footnotetext{
${ }^{1}$ English as a Foreign Language.
} 


\section{PRINCIPLES OF VocABULARY TEACHING IN LITERATURE} AND THE PURPOSE OF THIS ARTICLE

Vocabulary, as a linguistic term, may be defined as the stock or repertoire of words used in a language. It has been defined as "a language user's knowledge of words" (Gairns, 1986), or "the system of techniques or symbols serving as a means of expression as in arts or crafts" (Allen, 1983). It has got hundreds of formal definitions by linguists, anthropologists, psychologists and academics of other related disciplines, all of which unanimously see vocabulary as a set of words known to human beings, or smallest meaningful (lexis) or functional (function words) elements of a language.

In recent times, it is commonly acknowledged that vocabulary teaching should be part of the educational institutions' language syllabus and taught on a regular basis. The availability of hundreds of books of vocabulary learning organized categorically, and even more research articles and books on vocabulary instruction adequately assert on vocabulary as a special component in language syllabus instead of incidental instruction. Lewis (1993) argues that vocabulary should be at the centre of any language teaching syllabus because "language consists of grammaticalised lexis, not lexicalised grammar".

James Coady (1997) summarizes the teaching of second language vocabulary in some broad aspects. According to him, 'three main principles' seem to underlie effective vocabulary teaching. First, learners should be provided with both "definitional and contextual information about words". In the case of L2 learners, this could be related to their often-felt need for dictionary access. Second, learners should be encouraged to "process information about words" at a deeper level. Among L2 learners, this could be reflected in the current emphasis on authentic communicative activities. Finally, learners need "multiple exposures to words" that may come from the extensive fun reading or the listening/watching of interesting audiovisual stuff. Thus, Coady's principles highlight the varied contexts of vocabulary that learners have to note and emphasise the need for multiple paths of approaching new words.

Brown \& Perry (1991), focusing on the keyword method and semantic processing techniques, provide the principle of "depth of processing" (Craik \& Lockhart, 1972; Craik \& Tulving, 1975) in vocabulary teaching. Precisely speaking, the idea is that "when more cognitive resources are used in processing a word or phrase - more attention is paid". When a learner glances at a word and recognizes the letters, that is one level achieved and a very superficial one. When the context is brought to bear the meaning, the learner's past experience is associated, and schema is active, a complete semantic processing takes place - at a very deep level. Brown and Perry thus set the mental linkage system as a significant principle of vocabulary teaching-learning.

Nation (2001) simplifies the whole matter of teaching-learning vocabulary in a foreign language by anchoring it in three major aspects of words: meaning, form, and use. Breaking down these three into smaller and detailed components, he provides respective vocabulary learning contents and then suggests exercises accordingly. Nation's aspects thus emphasize the lexes as a multifarious phenomenon.

While the above principles are significant, they can be revisited to be set as important considerations in teaching vocabulary to the advanced learners. The list may be enriched by also including more similar considerable grounds that can be extracted from literature and/or vocabulary teaching books/materials. The focus of the present article is not to provide any strategy of vocabulary teaching. There are plenty of literature and online and offline teaching books and materials that can help in this regard. This paper rather aims to sort out and 
elaborate on the common grounds/principles underlying those strategies. By 'grounds' we mean the guiding principles that can help identify both the problems and remedies and provide suitable strategies and their useful techniques. As hinted above from Coady, Brown \& Perry, and Nation, varied contexts of vocabulary or Lexis as a complex entity, multiple paths, and mental linkage system are the examples of such grounds.

The following sections propose and elaborate five major 'grounds' of teaching vocabulary as to possibly cover the relevant theories and approaches like the above ones and to tune them to the distinct need of the advanced learners. These aspects are as follows:

a. Ground One: 'Cross Binary Network' of Vocabularies

b. Ground Two: Lexis as a Multifarious Phenomenon

c. Ground Three: A Mental Storage System for a Wider Range of Vocabulary

d. Ground Four: Learner Autonomy

e. Ground Five: Creating Multiple Paths

Instead of necessarily supporting or opposing any methods or strategies, we intend to provide in a summative manner the common categorical aspects underlying all possible considerations of teaching-learning vocabulary.

\section{GRound OnE: 'CROSS Binary NetWorK’ OF Vocabularies}

From a language learner perspective vocabulary actually comprises the four dimensions, that of listening, speaking, reading and writing, and as they have differences, we can conveniently talk of 'vocabularies' (e.g. listening vocabulary, reading vocabulary, writing vocabulary, and speaking vocabulary) instead of just 'vocabulary'. 'Listening vocabulary' is made up of all the words learners hear and understand but do not necessarily use in their own speech. 'Speaking vocabulary' includes all the words students hear and use in everyday speech. 'Reading vocabulary' consists of the words in print that learners can read and understand. 'Writing vocabulary' includes words that students can understand when listening and reading, and can reproduce when writing.

Primarily vocabularies are of two types: receptive that comprises words that are generally understood when heard or read/seen, and productive that generally refers to words which can be produced within an appropriate context and match the intended meaning of the speaker or writer. A person's receptive vocabulary is naturally the larger of the two types except for the cases of difficulties in comprehension from listening caused by accentual barriers. This is because our mind can and does store much more than we use in a given situation. A computer can be used as its best example, which can give an output of say, a one-page print only after having a hundred times more input like an operating system (Windows), an application software (MS Office), and a printer driver installed. Within the receptiveproductive distinction, there lies a range of abilities often referred to as the degree of knowledge based on the cognitive stages like recognizing a word, identifying it with its forms, functions, and partners (collocation), using it with difficulty, or using it fluently.

Understanding the interconnectivity of the aforementioned four vocabularies based on the four universal language skills is necessary to find out the gaps in an EFL learner's overall vocabulary range and decide accordingly about the proper teaching-learning of vocabulary. Having receptive-productive distinction on one side and sharing auditory (listening-speaking) or visual (reading-writing) medium on the other, the relationship between vocabularies can be seen as a double-binary or cross-binary network (Figure 1). 
While they share the same medium i.e. audio channel, speaking vocabulary (SV) as a measurable collection is always less (equation 1) than listening vocabulary (LV) for production being more challenging and involving more complex mental efforts than reception. Similarly, while sharing the same visual channel, writing vocabulary (WV) as a measurable chunk is always less (equation 1) than reading vocabulary (RV) for the same productive-receptive dichotomy.

$$
\begin{array}{rlrl}
\text { I. } & & \mathbf{L V}>\mathrm{SV} \text { and } \\
& \mathbf{R V}>\mathrm{WV}
\end{array}
$$

Again,

\section{II. $\quad(\mathrm{SV}<\mathrm{WV})<(\mathbf{L V}<\mathrm{RV})$}

Equation 1: Comparative size of vocabulary

\section{If, $\mathbf{S V}=\mathbf{A}$,}

Then,

$$
\begin{aligned}
\text { I. } & \text { WV is: } A+1=B \\
\text { II. } & \text { LV is: } A+B+1=C \\
\text { III. } & R V \text { is: } A+B+C+1=D
\end{aligned}
$$

Equation 2: Size and mutual involvement of vocabularies chunks involved

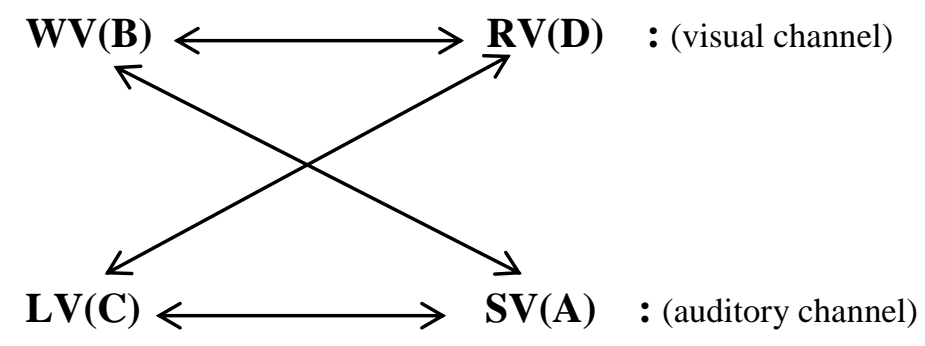

(receptive)

(productive)

Fig. 1 Cross-binary relation of language skills and vocabulary

While the productive-receptive (PR) dichotomy is absolute in determining the size of a vocabulary on inter-relationship with the other (auditory-visual) duality, it is rather relative and hazy on its intra-relationship, taking the two productives (writing-speaking) or the two receptives (reading-listening) in homogeneous/parallel pairs. Generally based on the availability of a space for reflection we can assume that writing vocabulary in the first pair and reading vocabulary in the second will be respectively bigger than speaking and listening (Equation 2). This is because a person while producing a language outcome normally gets more time and personal space of reflection (to go back, repeat, correct and revise) in writing than in speaking. Similarly, while receiving / comprehending a language input s/he gets more opportunity of reflection (going back, repetition, correction, and revision) in reading than in listening. To add on it, unlike writing and reading, in speaking and listening we are engaged in an instant message transaction that gives little chance of modifying our acts of coding/producing suitable words (in speaking) and decoding/receiving proper meaning (in listening). 
However, in an age of domination of visual media the above assumption may not always give the real picture particularly of the young users of the language. Nowadays with a drastic decrease of reading and writing habits and increase of watching movies or other visual stuff and thereby limiting communication to speaking/chatting over phone or internet, it may not be surprising that many language users' speaking and listening vocabularies are stronger than that of writing and reading (personal informal interview notes, September 2009-December 2014).

This four-skill based 'cross-binary network's (as I name it) connection to vocabularies is vitally important to find out the range, scope and employable strategies for the learners at the university level. At this stage, we are concerned not only about the students' ability to understand the meaning of words but also about their capability to use them appropriately while taking into account factors such as oral or written use of the language; degree of formality, style and others. So far Bangladesh education system is involved, it is at the university level that students for the first time need to read and write a lot on different academic topics (mostly available in English) that they rarely had to do in the earlier years of education. So the enhancement of RV and WV becomes particularly important at this stage. As to talk about the university students' newly found sources of advanced vocabularies, LV is acquired from university class lectures, seminars and workshops, SV from academic interactions with teachers and peers, and RV from the subject related books and articles. WV, being the most formal and reflective, involves all other vocabularies to be used in an organized, consistent and purposeful manner. The last one becomes crucial in final exams which are written and usually require a lot of writing.

\section{GROUND TwO: LEXIS AS A MULTIFARIOUS PHENOMENON}

There are several aspects of lexis that need to be taken into account when teaching vocabulary to the advanced learners. According to the work of Gairns \& Redman (1986), these are Homonymy, Homophony, Synonymy, Affective meaning, Style, Register, Dialect, Translation, and so on. As Thornbury (1998) points out,

"learning vocabulary is a challenge for learners, partly because of the size of the task, and partly because of the variety of vocabulary types to be learned, including single words, phrases, collocations, and strategic vocabulary, as well as grammatical patterns, idioms, and fixed expressions." (p. 23)

So, for instance, a learner needs to know the polysemantic differences of meaning of the word 'capitalize' in the sentences: (1) 'Capitalize the names of days and months even in the middle of sentences. '; (2) 'Capitalize the situation against your competitors.'; (3) 'Capitalize the amount for further investment.' This implies that the goals of vocabulary teaching must be more than simply covering a certain number of words on a word list. We must use teaching techniques that can help realize the varied aspects of mastering vocabulary and knowing a lexical item in detail.

Nation (2001) and Richards (1985) list the different things learners need to know about a word to learn it perfectly and conveniently. These include:

- The meaning(s) of the word and its spoken and written forms;

- Its grammatical behavior (e.g., its word class, typical grammatical patterns it occurs in); 
- What 'word parts' or morphological segments it has (e.g., any prefix, suffix, and 'root' form);

- Its register (connection to a particular usage area);

- Its collocations (word partners) and what connotations (extra-literal or suggestive meanings) it has;

- Its frequency of use;

- What associations it has (e.g., words that are similar or opposite in meaning).

\subsection{Discipline-based word collections}

While all the above components of words are important, discipline-based word collection involving a frequent disciplinary collocation is of particular relevance and importance to the advanced learners of the tertiary level, because at this stage learners for the first time get into discipline-wise specialization. There can be broad categories like Scientific Vocabulary, Business Vocabulary, or more specific ones (or register based words) like legal words, finance words, philosophic words, architecture words, fine arts words, physics words, and so on. It should not be confused with disciplinary terms or technical terms of a discipline; for they are special constructs purposefully built for the need of a respective discipline unlike the frequently used words of a discipline that get a contextual association therein.

Discipline-based dictionaries are good sources of this. Many websites are available on the internet for enhancing the practice of discipline-based words. Business Vocabulary and Scientific Vocabulary are two best examples, for which huge materials are available with innovative exercises. One best web collection for the broader academic needs of universitylevel students is "Academic Word Sublists" put together by a group of researchers at the Victoria University of Wellington, New Zealand. As the website describes it, the AWL (Academic Word List) is a list of words which appear with high frequency in Englishlanguage academic texts, including the Arts (history, psychology, sociology, etc.), Commerce (economics, marketing, management, etc.), Law, and the Sciences (biology, computer science, mathematics, etc.). The list was compiled following an analysis of over 3,500,000 words of academic journals, textbooks, course workbooks, lab manuals, and course notes.

\section{GROUND THREE: A MENTAL STORAGE SYSTEM FOR A WIDER RANGE OF VOCABULARY}

Understanding how our memory works might help us create more effective ways to teach/learn vocabulary at tertiary or advanced levels. Research in the area as cited by Gairns (1986) offers us some interesting insights into this process. It appears that learning new items involves storing them first in our short-term memory, and afterward in longterm memory. We do not control this process consciously. There are some important dimensions for retaining new words which we need to consider. According to Gairns (1986), "retention in short-term memory is not effective if the number of chunks of information exceeds seven" (p.76) (implying its short limit if not specifying the number). It suggests that in a given class we should not aim at teaching more than this number. However, our long-term memory can hold any amount of information.

Research also suggests that our 'mental lexicon' is highly organised and efficient and that semantically-related items are stored together. Word frequency is another factor that affects storage, as the most frequently used items are easier to retrieve (Elfrieda and Michael, 2003). We can use this information to attempt to facilitate the learning process, 
by grouping items of vocabulary in semantic fields, such as topics (e.g. types of fruit). As Willis (1996) suggests, the following strategies may aid widening and strengthening advanced learners' 'mental lexicon':

- "creating mental linkages: grouping, associating, placing new words into a context;

- applying images and sounds: using imagery, semantic mapping, using keywords and representing sounds in memory;

- reviewing in a structured and organized way; and

- employing action: utilizing physical response or sensation, using mechanical techniques, and acting out situations in language classes" (p.27)

However, in our view, Willis' techniques can be used with a greater convenience and consequence, if we detect 'learning style preferences' (i.e. visual, aural, kinesthetic, tactile) and "make students aware of different memory strategies" (Scrivener, 2005: p.22) suitable to their preferred style. Meaningful tasks, however, seem to offer the best answer to the challenge of vocabulary learning, as they rely on students' own experiences and reality to facilitate learning. They help them retain information in long-term memory.

\subsection{Retrieving the learned words when needed}

Forgetting seems to be an inevitable process with students learning vocabulary, and unless learners regularly use the items they have learned, it is very difficult to retain the items. Therefore, recycling is vital and, ideally speaking, it should happen one or two days after the initial input. The way students store the learned items can also contribute to their success or failure in retrieving them when needed.

Most learners simply list the items learned in a chronological order, associating meaning with translation. This system is far from helpful, as items are decontextualised, encouraging students to overgeneralise their usage. It does not allow additions and refinements, nor does it indicate any pronunciation. In my experience (supported by peer teacher discussions), students most of the time take the help of conventional wordbooks available in the market and memorise them in order to develop vocabulary. Some of them even start memorising the important words from dictionaries. But they find it very difficult to reproduce the words when necessary and actually more forget than learn. It is basically because of the afore-mentioned whimsical heaping of words and ignorance of the context and ambiguity of words.

\section{GROUND FOUR: LEARNER AUTONOMY}

As it is true about other areas of education, an important aspect of vocabulary teaching for advanced learners is to foster learner independence. It will help these learners, who have been newly independent after entering the university premises, to deal with new lexis and expand their vocabulary beyond the confinements of the course. Therefore, as Moras (2001) suggests, comprehension activities based on guided discovery and contextual guesswork, and proper use of dictionaries can be truly useful to deal with discovering and expanding meanings.

"Guided discovery" involves "asking questions or offering examples that guide students to guess meanings correctly" (Moras, 2001: p.34). In this way, learners get involved in a process of semantic processing that helps learning and retention. Good examples are those of "NTC Vocabulary Builders" by Pete Fisher (2001), and Comprehension books like "Exercises in Reading Comprehension" by Tibbits (2005), which are rich in this sort of word and meaning discovery exercises. 
"Contextual guesswork" means "making use of the context in which the word appears to derive an idea" (Moras, 2001: p.35) from its meaning, or in some cases, guesses from the word itself. Knowledge of word formation (Nagy, Herman \& Anderson, 1985), e.g. prefixes and suffixes, can also help students to discover meaning. Teachers can help students with specific techniques and practices in contextual guesswork for autonomous reading and listening.

EFL dictionaries can facilitate learning autonomy of the advanced learners. Although a word is never limited to the contexts shown as examples in dictionaries, they can indeed help to get an impression of the range of meanings involved with a word. With the adequate training of judicious use, dictionaries can become an invaluable tool (Hill, 1999), especially for advanced learners, giving them independence from teachers. Dictionaries are based on corpus analyses (Facchinetti, 2007: p.33) that include:

- "Frequency: Which words and expressions are most frequent and which are rare;

- Differences in speaking and writing: Which words are more often spoken and which are more often written;

- Contexts of use: The situations in which people use certain words;

- Collocation: Which words are often used together;

- Strategic use of vocabulary: Which words and expressions are used to organize and manage discourse."

Cambridge Advanced Learners' dictionary, for example, comes with all the above aspects suitably designed for university level learners. With the help of this, students can conceptualize varied meaning as well as check pronunciation, the grammatical aspects of the word (e.g. verb patterns, verb forms, plurality, comparatives, etc.), and different spellings (American versus British), with examples of their usage in sentences.

\subsection{Free reading as the ultimate source for independent learners}

For most teachers of English in Bangladesh and other EFL countries, 'vocabulary instruction is like spelling instruction', meaning that they know they ought to be doing it, but they do not generally know much about how. So they assign it rather than teach it, following how their own teachers taught. Customary vocabulary instruction is built on the assumption that knowing a definition is the same as thoroughly and flexibly knowing a word's meaning. The problem is often exacerbated by the misuse of dictionaries that provide meanings at best in a sentence, not the whole context. However, word meanings from a large comprehensible context are achieved only through voluntary reading or 'reading for pleasure'.

The sentential context of an unfamiliar word tells us something about its meaning, but seldom does any single context or some two or three collected in dictionaries give complete information. So reading is the ultimate remedy for this problem. Nagy et al. (1985) find that

"students who read grade-level texts under natural conditions have between a 5 to 20 percent chance of learning the meaning from a single isolated exposure. Further, if they spend about twenty-five minutes a day reading, they encounter about twenty thousand unfamiliar words." (p.238)

If the aforementioned 5 percent, or one twentieth, of those words can be figured out from a whole context, a child learns about a thousand new words from that strategy. In fact, Nagy et al. (1985) establish that the amount of time spent on reading is the best predictor of vocabulary growth. So, we need to use instructional strategies that accommodate and inspire free reading as a source of enhancing vocabulary and actively teach the use of context clues in reading instead of checking any word in a dictionary. 
Table 1. Creating multiple paths of teaching vocabulary

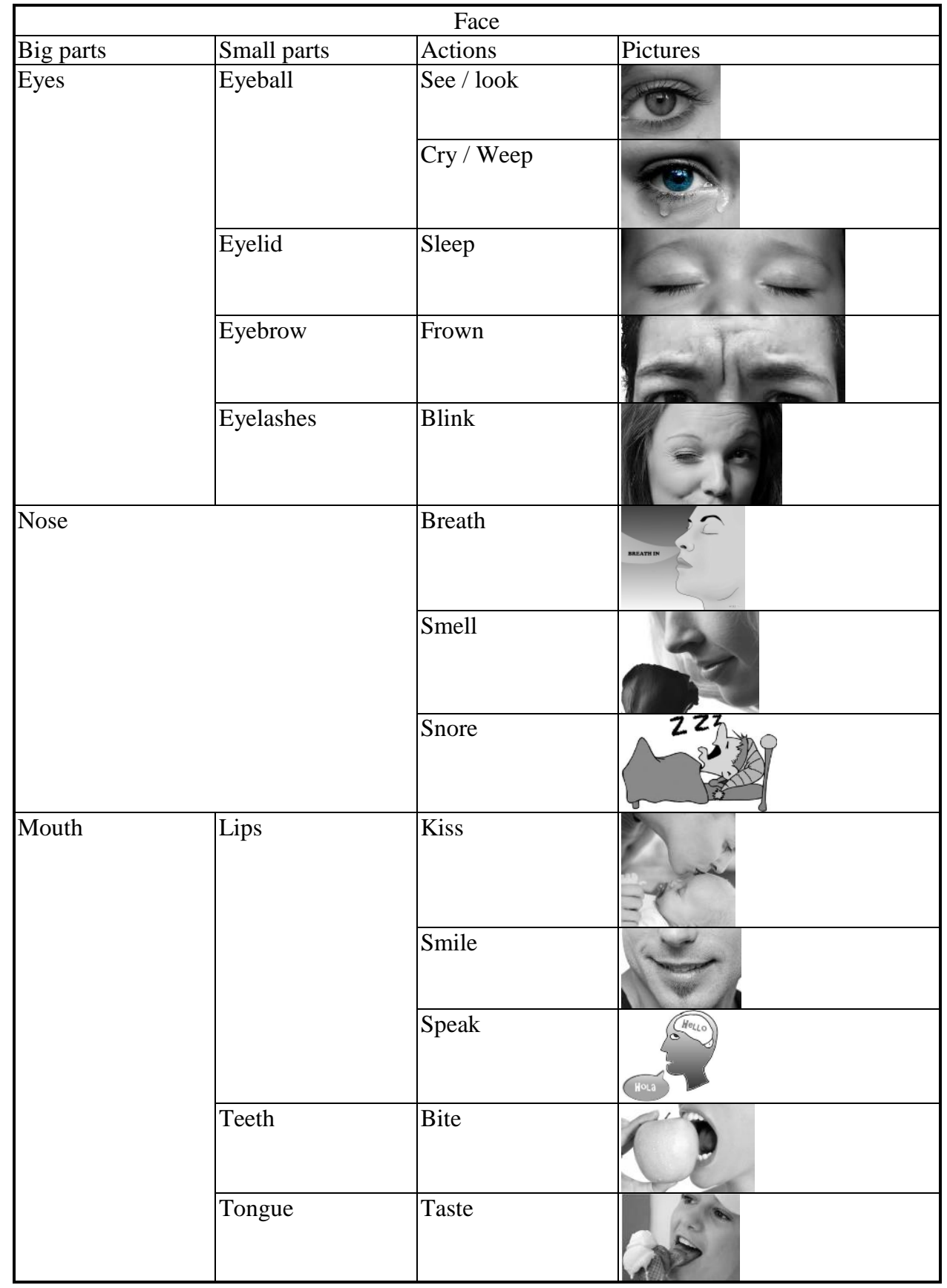




\section{GROUND FIVE: CREATING MulTiPle PATHS}

Use of multiple paths like text, graphics, sound, and video offers opportunities for employing a variety of learning styles. As the advocates of constructivism suggest (Vygotsky, 1978; Brooks \& Brooks, 1993), if the same content is offered in multiple media, it builds multiple pathways in memory, and more routes to the information make it easier to recall. It also helps to combine multiple domains of learning i.e. cognitive, affective, and psychomotor (Bloom \& Krathwohl, 1956; Harrow, 1972) in teaching vocabulary.

In an English language classroom, for instance, to teach the parts of our face and their uses, first we can put each part with their actions in a corresponding table (e.g. nose: smell/breath; lips: smile/kiss; tongue: speak/taste), then draw or present pictures of the organs along with their respective actions, and finally act out each action respectively (Table 1). Thus cognitive and psychomotor domains of learning are combined in teaching the relevant words in a complex web of relationship. Such type of dealing with vocabulary simultaneously brings in multiple media and varied classroom activities to ensure a constructive and sustainable learning of vocabulary.

\section{IMPLICATIONS FOR TEACHERS AND CONCLUSION}

In Bangladesh, vocabulary learning is mostly done by learners themselves usually with wordbooks and dictionaries. This is inadequate for the university-level students who suddenly come across a vast range of academic words. Understanding the cross-binary connection of language skills and the respective vocabularies, having insight into the mental storage process, recognizing words in bigger contexts through reading, dealing with multiple aspects of meanings and using multiple paths for varied individual learning styles are the key aspects in this regard. Accordingly, an English teacher teaching vocabulary to advanced learners with the five grounds in mind can do the following.

a. For ground one (the networks of vocabularies), of all the four language skills emphasize reading the most. Provide interesting resources for reading according to the topic areas of the respective student's major subject/discipline. Speak slowly and clearly in class and tutorial sessions and keep the words within the range of the students' understanding. Bring in new/difficult words step by step.

b. For ground two (multiple aspects of words), provide some details (word segments, grammatical function, collocation, subject-specific meaning, synonyms and antonyms, homophones and homographs) of the newly appearing words, especially the keywords. Also, prepare a list of say 100-300 words that are most important and frequent in the respective major subject and give it in advance.

c. For ground three (mental linkage), arrange the above list of words in relevant groups. Provide exercises based on discovery challenges and contextual clues.

d. For ground four (leaner autonomy), make the students use a good English dictionary and encourage free reading. Suggest relevant interesting things to read e.g. storybooks, novels, newspapers, magazines and so on.

e. For ground five (multiple paths), employ multiple channels for teaching a given topic (and its related words) through writing on the whiteboard/blackboard, showing pictures, playing audio/video materials, providing sentences including the target words, acting out relevant actions, and so on. 
These grounds thus help to find the best possible ways of teaching-learning vocabulary and building a sustainable and useful word stock in mind to be readily used in language skills. With these major grounds in mind, obviously, we also have to continue exploring new techniques for utilizing the latest innovative teaching-learning schemes while keeping pace with the ever-changing needs of the academic disciplines.

\section{REFERENCES}

Allen, V. (1983). Techniques in Teaching Vocabulary. Oxford: Oxford University Press.

Arju, S. (2011). A study on ESL vocabulary acquisition needs and classroom practice: a Bangladeshi context. Stamford Journal Of English, Volume 6. Available at http://www.banglajol.info/index.php/SJE/

Bloom, B.S. \& Krathwohl, D. R. (1956). Taxonomy of Educational Objectives: The Classification of Educational Goals. NY: Longmans, Green.

Brooks, J.G. \& Brooks, M.G. (1993). In search of understanding: The case for constructivist classrooms. Alexandria: Association for Supervision and Curriculum Development.

Brown, T.S, \& Perry, F.L.J. (1991). A Comparison of Three Learning Strategies for ESL. Oxford: Oxford University Press.

Cambridge Advanced Learners' Dictionary. (2003). London: Cambridge University Press.

Clarke H. H., \& Clarke E. V. (1977). Psychology and Language: Introduction to Psycholinguistics. New York: Harcourt Publishers Ltd

Coady, J, \& Huckin, T. (1997). Second Language Vocabulary Acquisition. Cambridge: Cambridge University Press.

Craik, F.I.M., \& Lockhart, R.S. (1972). Levels of processing: A framework for memory research. Journal of Verbal Learning and Verbal Behavior, 11, 671-684.

Craik, F.I.M., \& Tulving, E. (1975). Depth of processing and the retention of words in episodic memory. Journal of Experimental Psychology: General, 104, 268-294.

Elfrieda, H. H., \& Michael L. K. (2003). Teaching and Learning Vocabulary: Bringing Research to Practice. New York: Lawrence Erlbaum.

Facchinetti, R. (2007). Theoretical Description and Practical Applications of Linguistic Corpora. Verona: QuiEdit.

Fisher, P. (2001). NTC Vocabulary Builders Series Book. McGraw Hill Publishers.

Gairns, R., \& Redman, S. (1986). Working with Words. Cambridge: Cambridge University Press.

Harrow, A. (1972). A Taxonomy of Psychomotor Domain: A Guide for Developing Behavioral Objectives. New York: David McKay.

Hill, J. (1999). Collocational Competence. English Teaching Professionals, 11, 3-6.

Lewis, M. (1993). The lexical approach: the state of ELT and a way forward. Hove: Language Teaching Publications.

Moras, S. (2001). Teaching Vocabulary to Advanced Students: A Lexical Approach. Karen's Linguistics Issues. July 2001 issue. Available at http://www3.telus.net/linguisticsissues/ teachingvocabulary.html

Nagy, W.E., Herman, P.A., \& Anderson, R.C. (1985). Learning words from context. Reading Research Quarterly, Volume 20, 233-253. 
Nation, I.S.P. (2001). Learning Vocabulary in Another Language. Cambridge: Cambridge University Press.

Oxford English Dictionary. Oxford: Oxford University Press. (2010)

Rahman, A. M. H. (1988). A Textbook on trial: English for today book eight. BELTA Journal 1 Richards, J. (1985). The Context of Language Teaching. Cambridge: Cambridge University Press.

Schmitt, N. (2000). Vocabulary in Language Teaching. Cambridge: Cambridge University Press.

Scrivener, J. (2005). Learning teaching: A Guidebook for English Language Teachers. Macmillan.

Thornbury, S. (1998). The Lexical Approach: A Journey Without Maps. MET, 7, 4-5.

Tibbits E. L. (2005). Exercises in Reading Comprehensions. Cambridge University Press.

Vygotsky, L. (1978). Mind in Society. London: Harvard University Press.

Willis, J. A._(1996). Framework for task-based learning. Longman.

WordWeb Software Dictionary. Available at www.wordweb.com

www.victoria.ac.nz/lals/resources/academicwordlist (accessed on $10^{\text {th }}$ September, 2012)

Yasmin, F. (2006). English language teaching in Bangladesh: An overview. The Dhaka University Studies, Volume 63.

\section{MATERIALS EXAMINED}

Compiled Course Book. (2009). Brought together by English Language Institute, United International University. Dhaka.

HUM 135, HUM 111, HUM 125 course materials. (2009). BUET (Bangladesh University of Engineering \& Technology, Department of Humanities. Dhaka.

English language course-book. (2009). University of Dhaka. Faculty of Arts and Humanities. 